\title{
Stormwater quality modeling in urbanized areas
}

\author{
Marek Zawilski ${ }^{1, *}$, Błażej Dziedziela ${ }^{2}$ \\ ${ }^{1}$ Lodz University of Technology, Institute of Envorinmental Engineering and Building Installations, \\ al.Politechniki 6, 90-924 Łódź, Poland \\ ${ }^{2}$ Lodz University of Technology, Institute of Envorinmental Engineering and Building Installations, \\ al.Politechniki 6, 90-924 Łódź, Poland
}

\begin{abstract}
Stormwater quality modeling with the use of Stormwater Management Model (SWMM) is presented. The model has been calibrated on the basis of measurements of flow and stormwater quality performed on a real catchment in Łódź, Poland. Calibrated model parameters and the correlations between the quality indexes are given. This will allow application of the model to other urban catchments equipped with storm drainage systems.
\end{abstract}

\section{Introduction}

The discharge of stormwater into natural waters poses the danger of hydraulic overload. At the same time, stormwater introduces significant loads of pollutants into the receivers that adversely affect the state of freshwater purity.

Modeling the composition of stormwater is useful for assessing their impact on the receiver, as well as for the selection of devices for its treatment. It also significantly eliminates the need to conduct labor-intensive and time-consuming studies on the quality of runoff.

Modeling procedures are present in many computer engineering programs (e.g. Stormwater Management Model - SWMM), but in order to be useful in practice, they require the input of a number of model parameters which can be determined only on the basis of realtime stormwater quality tests over a longer period of time performed on real urban catchments.

\section{Pollutants in urban stormwater and their origin}

Storm drainage is an important element of infrastructure in urban areas. Draining of the urbanized area was assumed, i.e. the area occupied by buildings and public transport facilities - roads, streets, car parks, tracks etc. Since, according to these assumptions stormwater was treated as a slightly polluted medium, the drainage had to ensure the hydraulic capacity of sewers and to minimize the possible flooding of terrain and underground structures, with the logical assumption of no risk of polluting the receiving waters. However, detailed research

\footnotetext{
*Corresponding author: marek.zawilski@p.lodz.pl
} 
on the composition of stormwater disavoed these common views, which began to be noticed already in the 1970s. Today, we know that the pollution of stormwater is closely correlated with the land use in the urban catchment and the rate of accumulation of pollution, mainly of anthropogenic origin. The composition of stormwater runoffs is very variable and related to the intensity of rainfall phenomena. The mechanism of formation of these pollutants includes two most important processes:

- the accumulation of pollution on the catchment surfaces in periods between rainfalls, as a result of dust fall, aerosols, solid waste accumulation, fuel and lubricant spills, as well as corrosion and abrasion processes,

- the wash-off of solid and soluble contaminants from the catchment area by surface runoff. Seasonal pollination of plants and leaf fall, as well as the phenomenon of sediment formation in the sewer network and their wash-off, are also of some importance.

Therefore, the most widespread methods for modeling the composition of sewage takes into account not only the first two processes mentioned above, but also the basic difficulty in the need to calibrate models, that is, to determine the numerical values for certain empirical model parameters. Until now, effective methods for their direct measurement have not been developed (e.g. the rate of accumulation of pollutants). The factor hampering modeling is the diversification of catchment management, and thus the existence of areas of different degrees of pollution, among which can be distinguished, for example, relatively polluted transport, industrial and storage areas, as well as less polluted peripheral areas of less intense development. Sometimes, the degree of catchment pollution also results from random factors.

On the other hand, the confirmed correlation between the total suspened solids (TSS) and other indexes, primarily COD and heavy metals, is the circumstance facilitating stormwater quality modeling. This is due to the adsorption of organic substances and heavy metal compounds on the suspended solid particles (or because oxides and heavy metal salts are part of them). Since solid pollutants are also a silting factor for natural receiving waters, the TSS index is standarized in the water protection regulations and is consequently considered as the basic one for stormwater quality modeling.

\section{Methods for stormwater quality modelling}

As mentioned above, hydrodynamic wash-off processes on the catchment area are important for the content of pollutants in stormwater, and therefore quantitative and qualitative modeling should be closely linked. Parameters of precipitation and surface runoff are therefore necessary both for modeling the volume of runoff directed into the sewerage as well as the washing-off of pollutant. It is assumed that a given rainfall is usually not able to transport all accumulated pollutants to the sewerage, so some of their mass remains on the catchment, adding to new mass accumulating again after the precipitation has stopped. In this case, for modeling stomwater quality it is necessary to know the entire annual rainfall continuum and not only a single reliable rainfall phenomenon, e.g. of assumed probability of occurrence and duration, which is typical for the hydraulic design of storm and combined sewerage.

The two basic formulas for modeling the accumulation of pollutants (1) and their washoff by rainfall runoff (2) have the following formula:

$$
\begin{gathered}
\frac{d L}{d t}=a t-w L \\
\frac{d L}{d t}=\left(k q_{\perp} e f^{\top} n L\right.
\end{gathered}
$$

where:

L - specific load of pollutants per unit of catchment area, 
a - specific rate of pollution accumulation per unit of time and catchment area,

$\mathrm{w}$ - so-called wind factor, decreasing the accumulation rate, dimensionless,

$\mathrm{k}, \mathrm{n}$ - empirical coefficients of pollutant wash-off,

$\mathrm{q}_{\mathrm{ef}}$ - intensity of effective runoff from the catchment area to the sewerage.

Both equations create an explicit deterministic model of the balance of pollutant mass on the catchment, and in principle they relate to the period of one year with a possible break for the winter period in the absence of a continuous rainfall continuum in our climate zone.

The supplemented Eq. (1) also takes into account a decrease in the accumulation rate due to a real or hypothetical sweeping of the catchment area (mainly streets and pavements) at a certain frequency. Also, the gross accumulation rate itself may be seasonally variable as, for example, based on measurements of dustfall.

In turn, Eq. (2) assumes the wash-off of pollutants from sealed surfaces only, and the intensity of surface runoff is identified with the intensity of effective runoff into the sewerage, i.e. taking into account reducing effects, e.g. evaporation and terrain retention. The load of washed-off pollutants is identified with that which is transported into the drainage system, and thus the detention of contaminants in the sewers and sediment traps is omitted (although these assumptions in more complex models should not be obligatory). In most cases, the rate of pollution wash-off is assumed to be the same for all sub-catchments, although formally its diversification is possible when the results of relevant tests are available.

As mentioned, due to the inability to directly measure the amount of accumulation and wash-off, it is necessary to calibrate the model for practical applicationson on the basis of real-world studies.

\section{Studies on real catchments and calibration problems}

Globally, as well as in Poland, several studies on real urban catchments have been performed $[1,2,3,4]$. They have made it possible to confirm the general assumptions of the model (Eq. (1) and (2)); however, they were carried out using equipment of an older generation which did not often provide the required measurement accuracy. This was particularly true for the intensity of rainfall, which is in fact is very variable in time and space [5]. In turn, data from world literature indicate a significant influence of local factors, which is reflected in discrepancies in the values of calibrated model parameters.

\section{Research procedure on a real catchment in Łódź}

During the period of 2013-2014, detailed research was carried out on one of the urban catchments in Łódź with the intention of verifying the model of the wash-off of pollutants by stormwater [6]. The studied catchment, having a residential character and a total area of 11.9 ha, is located in the northern part of the city and is equipped with separate sewerage (Fig. 1). Its characteristics are presented in Table 1. 


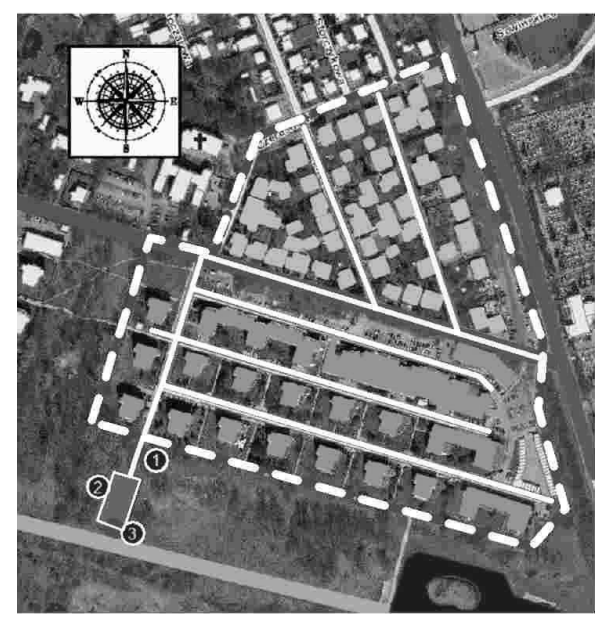

Fig. 1. Schematic of the studied urban catchment in Łódź. Dashed line represents the catchment border, continuous lines - main storm sewers, 1 - monitoring point, 2 - sedimentation tank, 3 - outlet to the receiving water.

Table 1. Land use of the studied catchment.

\begin{tabular}{|c|c|c|c|c|c|c|c|c|}
\hline & \multicolumn{5}{|c|}{ Sealed } & \multicolumn{3}{|c|}{ Non-sealed } \\
\hline Surface type & Sett & Sidewalk & Asphalt & Roofs & $\begin{array}{c}\text { Semi- } \\
\text { pervious }\end{array}$ & $\begin{array}{c}\text { Green } \\
\text { areas }\end{array}$ & $\begin{array}{c}\text { Green } \\
\text { roofs }\end{array}$ & $\begin{array}{c}\text { Natural } \\
\text { soil }\end{array}$ \\
\hline Area [ha] & 1.05 & 1.34 & 0.82 & 1.99 & 0.46 & 5.92 & 0.16 & 0.15 \\
\hline $\begin{array}{c}\text { Imperviousness } \\
{[\%]}\end{array}$ & 80 & 70 & 95 & 99 & 50 & 3 & 10 & 10 \\
\hline
\end{tabular}

The catchment is equipped with a separate sewer system, and the storm drainage directs stormwater into the detention-sedimentation tank and onward to the Sokołówka River (Fig. 1).

At the inlet to the tank, a flow meter module and OCM PRO CF NIVUS control panel were installed as well as the Teledyne Isco automatic sampler 6712FR. The sampling, a representative volume of stormwater at the inlet, occurred after exceeding the specified sensitivity threshold of the sewer depth (several $\mathrm{cm}$ ), with the volume intake interval determined depending on the forecasted intensity of rainfall.

At the same time, rainfall measurements were made with a 5-minute time-step at 6 stations of the municipal pluviometric network, on the basis of which the intensity of precipitation for the centre of gravity of the catchment was interpolated.

The range of laboratory analyses of pollution indexes included the total, mineral and organic suspended solids, COD and turbidity. In selected samples, Kjeldahl nitrogen, total phosphorus, conductivity, heavy metals and petroleum-derived substances were also determined. In order to check the level of the catchment's contamination, an own station for measuring dust fall was also set (state air quality monitoring services gave up this measurement some time ago). For the study period, the mean value of dust fall as $15 \mathrm{~g} / \mathrm{m}^{2} \cdot \mathrm{d}$ has been detected. 


\section{Results of stormwater modeling}

The model of the catchment under study was created in the SWMM program (Fig. 2).

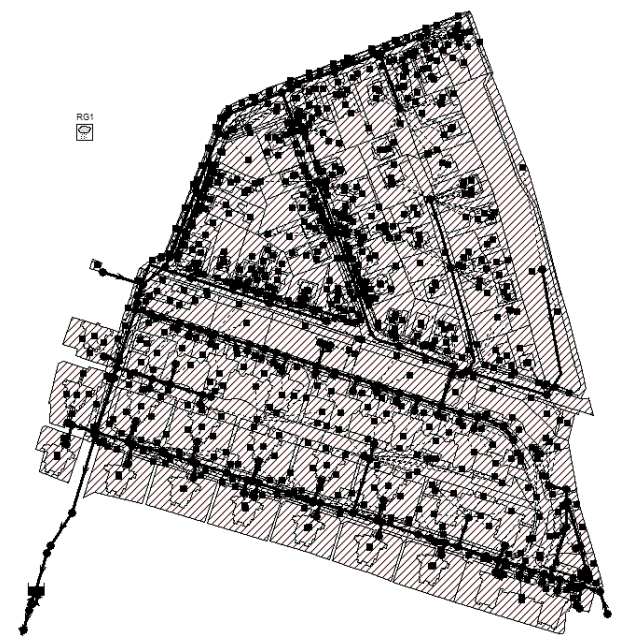

Fig. 2. Schematic of the catchment model created in the SWMM program.

On the basis of the measurements for rainfall intensity and flow rate from the catchment to the sedimentation tank, the hydraulic model was calibrated. In total, 84 well-recorded precipitation phenomena from 2012-2015 were selected for the calibration. The quality of the fitting of the model concerning the courses of the flow rate (hydrographs) was determined using the equation proposed by Nash and Sutcliffe [7]:

$$
N S E=1-\frac{\sum_{i=1}^{n}\left(Q_{P, i}-Q_{M, i}\right)^{2}}{\sum_{i=1}^{n}\left(Q_{P, i}-\overline{Q_{P}}\right)^{2}}
$$

where:

$\mathrm{Q}_{\mathrm{P}, \mathrm{i}}-$ recorded flow rate in a given time-step $\left[\mathrm{dm}^{3} / \mathrm{s}\right]$;

$\mathrm{Q}_{\mathrm{M}, \mathrm{i}}-$ modeled flow rate in a given time-step $\left[\mathrm{dm}^{3} / \mathrm{s}\right]$;

$\overline{Q_{P}}-$ average recorded flow rate during measurements $\left[\mathrm{dm}^{3} / \mathrm{s}\right]$;

$\mathrm{n}$ - number of time steps [-].

The values of final model parameters are presented in Table 2.

Table 2. Parameters of the hydrological and hydraulic SWMM model obtained in calibration.

\begin{tabular}{|c|c|c|c|}
\hline Parameter & Symbol & Unit & Value \\
\hline Coefficient of hydraulic width of runoff* & $\mathrm{k}^{*}$ & - & 0.5 \\
\hline Mean catchment slope & $\%$ Slope & $\%$ & $2.0-7.0$ \\
\hline Manning coefficient for imprervious surfaces & N- Imperv & - & 0.02 \\
\hline Terrain storage for imprervious surfaces & Dstore-Imperv & $\mathrm{mm}$ & 2.5 \\
\hline Percent of smooth surfaces without terrain storage & \%Zero-Imperv & $\%$ & 25 \\
\hline Maximum infiltration rate into the ground & Max.InfiRate & $\mathrm{mm} / \mathrm{h}$ & 90 \\
\hline Minimum infiltration rate into the ground & Min.InfiRate & $\mathrm{mm} / \mathrm{h}$ & 5 \\
\hline
\end{tabular}

* hydraulic width $\mathrm{W}=\mathrm{k} \sqrt{\mathrm{A}}$, where $\mathrm{A}$ - area of subcatchment. 
The calibration resulted in a good fit for the model to the measurements - for 80 selected precipitations the condition NSE $>0.65$ is met, which is accepted as a satisfactory criterion; and only 4 phenomena that did not meet this criterion were rejected.

The final assessment of the quality of the fit of the model was made on the basis of the correlation of the maximum flow and inflow volume.

The next stage of numerical analyses was the calibration of the pollution wash-out model and its verification in the SWMM program. The basis for modeling was Eq. (2), however the notation of model parameters were adequate to the SWMM user manual. For Eq.(2) the SWMM model uses the maximum accumulation of pollutants as a limiting value per unit area. The effective runoff intensity is determined in a calibrated hydrological model (described above). In order to properly describe the pollutant wash-off and resulting pollutographs, it was necessary to distinguish surfaces of the varying degree of pollutant accumulation (like the maximum for all streets and sidewalks), which reflects the strong variation in the concentration of pollutants in the initial phase of the runoff (the so-called first flush phenomenon) and which revealed the results of previous studies [1,2,3]. Also, the frequency of sweeping roadways and sidewalks, as well as the length of the dry weather period before precipitation was assumed. However, this value is only significant for the early spring until the first precipitation (for the remaining period of the year it is automatically determined from the annual rainfall continuum).

The results of the wash-off model calibration for the total suspended solids indicator are shown in Table 3.

Table 3. Parameters of the wash-off SWMM model program obtained in calibration.

\begin{tabular}{|c|c|c|c|c|}
\hline Parameter & Equivalent in SWMM & Symbol & Unit & Value \\
\hline $\begin{array}{c}\text { Limiting accumulation of } \\
\text { pollutants on polluted } \\
\text { surfaces }\end{array}$ & Max buildup & $\mathrm{C}_{1}$ & $\mathrm{~kg} / \mathrm{ha}$ & 500 \\
\hline $\begin{array}{c}\text { Limiting accumulation of } \\
\text { pollutants on less polluted } \\
\text { surfaces }\end{array}$ & Max buildup & $\mathrm{C}_{1}$ & $\mathrm{~kg} / \mathrm{ha}$ & 50 \\
\hline $\begin{array}{c}\text { Coefficient of accumulation } \\
\text { reduction=wind factor }\end{array}$ & Rate constant & $\mathrm{C}_{2}$ & $1 / \mathrm{d}$ & 0,15 \\
\hline Street sweeping efficiency & Cleaning coefficient & $\eta$ & $\%$ & 80 \\
\hline $\begin{array}{c}\text { Period of dry weather before } \\
\text { the rainfall }\end{array}$ & Antecedent dry days & $\mathrm{t}_{\mathrm{o}}$ & $\mathrm{d}$ & 5 \\
\hline $\begin{array}{c}\text { Period between street } \\
\text { sweeping }\end{array}$ & Street sweeping interval & $\mathrm{t}_{\mathrm{z}}$ & $\mathrm{d}$ & 14 \\
\hline $\begin{array}{c}\text { Availability of pollutants } \\
\text { during street sweeping }\end{array}$ & Availability & $\mathrm{d}$ & - & 1.0 \\
\hline \multicolumn{2}{|c|}{ Assumed in wash-off model } & $\mathrm{C}_{3}$ & - & 0,004 \\
\hline Wash-off rate & Coefficient & $\mathrm{C}_{4}$ & - & 1,8 \\
\hline Power coefficient & \multicolumn{2}{|c|}{ Exponent } & & \\
\hline
\end{tabular}

The verification of the obtained model of pollutant wash-off was carried out similarly to the hydrodynamic model. The course of the measured and modeled pollutographs was compared, and the final evaluation was the correlation of the measured and modeled TSS loads from each best 80 studied phenomena (Fig. 3). 

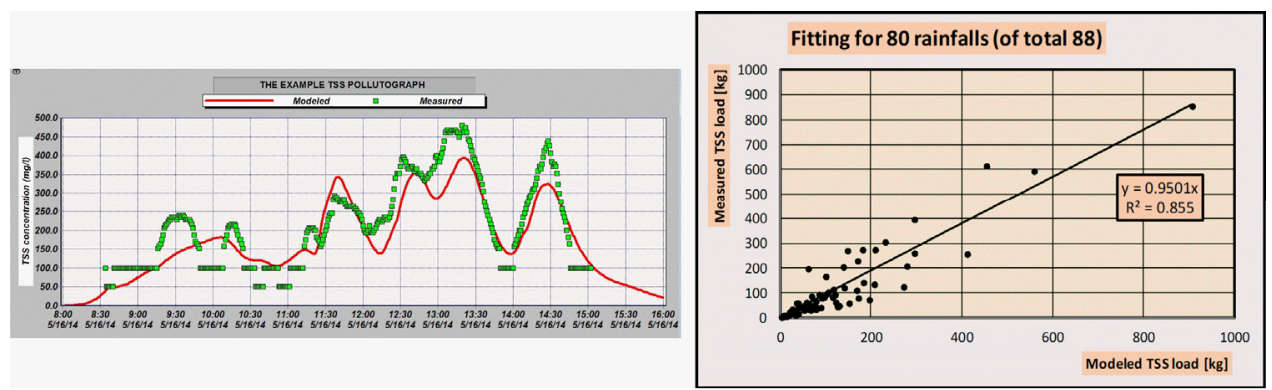

Fig. 3. Example pollutograph (left) and fitted TSS loads from all rainfall phenomena.

For the COD index a fairly clear correlation with the total suspended solids was obtained:

$$
C O D=0.47 T_{S S}^{0.91}+59.7
$$

with the determination coefficient $\mathrm{R}^{2}=0.93$.

Similarly, the relationship between TSS and turbidity (M) was obtained:

$$
T S S=e^{4.88+0.005 M}
$$

with $\mathrm{R}^{2}=0.92$.

This correlation indicates that the increase in the concentration of TSS is not proportional to the increase in turbidity, which is associated with changes in the fractional composition of the TSS - the presence of heavier particles at higher concentrations with a moderate increase in turbidity.

The relationship between the weighted average concentration of TSS and precipitation parameters was also analyzed. Using the multiple regression algorithm, the following optimal relationship was obtained with $\mathrm{R}^{2}=0.92$ :

where:

$$
\bar{c}=14.6 \frac{1}{t}+64.8 I_{\text {mean }}+A D W P^{1} .51+150 \pm 155
$$

$\overline{\mathbf{c}}$ - average weighted TSS concentration, $\left[\mathrm{mg} / \mathrm{dm}^{3}\right]$;

$\mathrm{t}-$ rainfall duration, [d];

ADWP - anteceded dry weather period, [d];

$\mathrm{I}_{\text {mean }}-$ mean rainfall intensity, $[\mathrm{mm} / \mathrm{h}]$.

\section{The use of model calculations}

A calibrated model of an urban catchment can be used to analyze the stormwater load to the receiver and to dimension water protection facilities. This applies in particular to the whole rainfall continuum for a given year, where one can distinguish several high-intensity rainfalls and a much larger number of weaker rainfalls. The model makes it possible to estimate the load of washed-off pollutants for the entire year, and not only for the studied rainfalls. For example, for 2013, for the analyzed catchment the total washed-off TSS load was obtained as $5050 \mathrm{~kg}$, which corresponds to a unit load of $1000 \mathrm{~kg} / \mathrm{ha}$ of sealed areas, and the three most intense rainfalls in that year gave a total TSS load of $30 \%$ of its annual value.

The model also allows studying the impact of the rate of pollution accumulation on the catchment as well as the sweeping frequency on pollutant emissions, and thus to assess the effectiveness of reducing the catchment pollution on receiving water contamination. 


\section{Conclusions}

1. As a result of the conducted research, the usefulness of the SWMM program for modeling stormwater quality in relation to TSS and COD, as well as to heavy metals due to their correlation with TSS index, was confirmed.

2. Obtaining the correct modeling data requires a detailed inventory of an urban catchment and the organizing of precise rainfall measurements,

3. The monitoring of dust fall make it easier to model stormwater quality,

4. It is necessary to diversify the sub-catchment pollution accumulation in order to correctly model the pollutographs,

5. The obtained results of the SWMM model calibration may be useful for urban catchments with similar land-use.

Scientific research has been carried out as a part of the Project "Innovative recourses and effective methods of safety improvement and durability of buildings and transport infrastructure in a sustainable development - the reduction of pollutant emission from urbanized areas into the environment", no. POIG.01.01.02-10-106/09-00 financed by the European Union from the European Fund of Regional Development and based on the Innovative Economy Operational Program.

\section{References}

1. M. Zawilski, G. Sakson G, Gaz, Woda i Technika Sanitarna, Nr 7, 272-275 (in Polish, contains the literature review) (2013)

2. M. Zawilski, G. Sakson G., Gaz, Woda i Technika Sanitarna, Nr 2, 57-59 (in Polish, contains the literature review) (2014)

3. M. Zawilski, Zeszyty Naukowe nr 792 Politechniki Łódzkiej, (in Polish) (1997)

4. B. Osmulska-Mróz, Prognosing and protection of freshwater on urban areas. Instytut Ochrony Środowiska, Warszawa (in Polish) (1992)

5. M. Zawilski, A. Brzezińska, Urban Water Journal, 11(7), 532-542 (2014)

6. B. Dziedziela, Ph.D. thesis, Poznań, (2017)

7. J. E. Nash, J. V. Sutcliffe, Journal of Hydrology, 10, 282-290 (1970) 